\title{
Rheological properties of polymer micro-gel dispersions
}

\author{
Dong Zhaoxia*, Li Yahua, Lin Meiqin and Li Mingyuan \\ Enhanced Oil Recovery Research Center, China University of Petroleum, Beijing 102249, China
}

\begin{abstract}
The influence of swelling time, temperature, $\mathrm{NaCl}$ concentration and polymer micro-gel concentration on rheological properties of polymer micro-gel dispersions was studied by using a HAAKE rheometer. The results showed that with increasing swelling time and $\mathrm{NaCl}$ concentration, the polymer micro-gel dispersions changed from a shear-thickening fluid to a Newtonian fluid. The polymer microgel dispersion show shear-thinning in non-saline water. At higher swelling temperature, the time of the polymer micro-gel dispersion showing shear-thickening was shorter. With increasing polymer micro-gel concentration, the dispersion changed from shear-thickening to shear-thinning.
\end{abstract}

Key words: Polymer micro-gel, rheological property, shear-thickening, shear-thinning

\section{Introduction}

In our previous work we have developed a linked polymer solution (LPS), which is used for in-depth profile control of oil-bearing reservoirs with water flooding (Dong et al, 2004; Li et al, 2000; 2004; Lin et al, 2004; 2007; 2008; Luo et al, 2006; Sun et al, 2005). Based on the research of LPS, polymer micro-gel dispersion has been developed in recent years in our laboratory for in-depth profile control of oilbearing reservoirs with high salinity formation water and high temperature (Han et al, 2006; 2008; Ma et al, 2006; Wang and xiao, 2008; Zong et al, 2007). The size of the polymer microgel is about $50-300 \mathrm{~nm}$ and the polymer micro-gel particles are hydrated and swollen in water during injection of the dispersions. As the polymer micro-gel dispersion is injected into oil-bearing reservoirs the rheological properties and the flow property of the dispersions affect the profile control and the enhanced oil recovery (EOR) significantly. In this paper we studied the influence of polymer micro-gel concentration, salinity of water, reservoir temperature and swelling time on rheological property of the polymer micro-gel dispersions.

\section{Experimental}

\subsection{Materials and preparation of samples}

The polymer micro-gel is a water/oil (W/O) microemulsion produced by Shengli-fanghua Company Ltd., China, with a content of the polymer micro-gel in the microemulsion of $20 \%$. The water used in the experiments was deionized water passed through a $0.22 \mu \mathrm{m}$ filter before use. The $\mathrm{NaCl}$ ( $\mathrm{GC}>99.5 \%)$ used was produced by Beijing Shuanghuan Chemical Factory, China. The polymer micro-

* Corresponding author. email: dzx@cup.edu.cn Received January 9, 2009 gel dispersions were prepared by mixing the polymer microgel micro-emulsion with different concentrations of $\mathrm{NaCl}$ solution. Swelling of the polymer micro-gel particles was carried out at $40^{\circ} \mathrm{C}$ and $90{ }^{\circ} \mathrm{C}$, respectively.

\subsection{Measurement of rheological parameters}

The rheological parameters of the polymer microgel dispersion were measured by using HAAKE RS 600 rheometer made by HAAKE company (German) at $30{ }^{\circ} \mathrm{C}$ after the samples were placed in the rheometer for 20 minutes.

For pseudoplastic (shear-thinning) and dilatant (shearthickening) fluids, the relationship between shear stress $\left(\sigma_{\mathrm{s}}\right)$ and shear rate $(\dot{\gamma})$ is expressed by a power law relation as follows:

$$
\sigma_{\mathrm{s}}=K(\dot{\gamma})^{n}
$$

where $K$ is the consistency coefficient, and $n$ is the nonNewtonian index. The larger the $K$, the more viscous the fluid is. For the pseudoplastic fluid, $n<1$, for the dilatant fluid, $n>1$, and for the Newtonian fluid, $n=1$. Taking logarithms of equation (1) gives:

$$
\lg \sigma_{\mathrm{s}}=\lg K+n \lg (\dot{\gamma})
$$

The curve of the logarithms of the shear stress $\left(\sigma_{\mathrm{s}}\right)$ versus the logarithms of the shear rates is linear with a slope of $n$ and an intercept of $K$. The rheological property of the polymer solutions fits the power law model (Lei et al, 1994).

\section{Results and discussion}

\subsection{Swelling time}

Fig. 1 shows the viscosity vs. the shear rate of the polymer micro-gel dispersion with $100 \mathrm{mg} \cdot \mathrm{kg}^{-1}$ polymer micro-gel and 


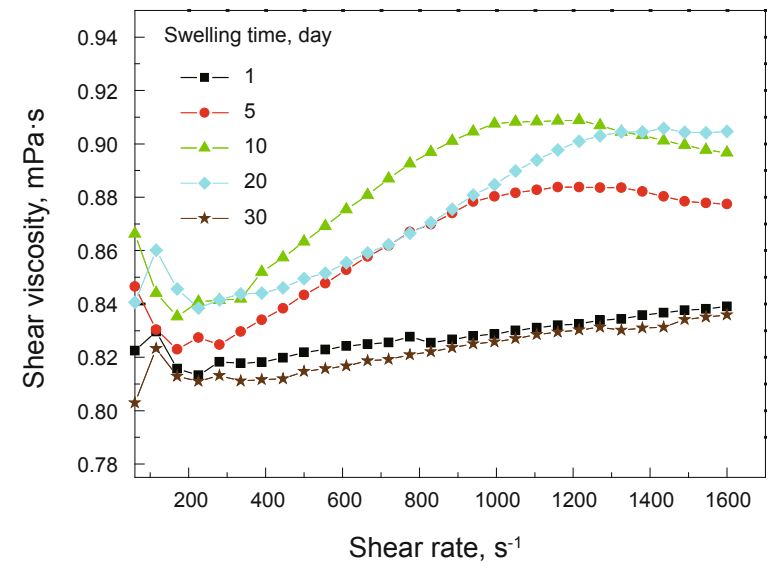

Fig. 1 Viscosity vs. shear rate of the polymer micro-gel dispersion with different swelling times

$2,000 \mathrm{mg} \cdot \mathrm{kg}^{-1} \mathrm{NaCl}$, for different swelling times at $40{ }^{\circ} \mathrm{C}$. The results showed that in the shear rates range of $225-1,215 \mathrm{~s}^{-1}$, with the increase of the swelling time, the dispersion changed from shear-thickening to Newtonian fluid.

According to the order-disorder transition theory (Hoffman, 1972; 1982) and the clustering theory (Brady and Bossis, 1985) (shown in Fig. 2), when the dispersion flows at very low shear rates, the polymer micro-gel particles have to move around each other or "bounce off "each other for overall flow to occur. On the other hand, the distribution of the particles remains essentially undisturbed because the Brownian motion dominates the shear motion and restores the randomness of the rest-state distribution. At high shear rates, the imposed velocity gradient induces an orientation of the polymer micro-gel particles, which could not be restored by the Brownian motion, and the particles form layer-ordered structures. The particles are oriented and move in their own layers independently (Barnes et al, 1989), so the dispersion is shear-thinning. At even higher shear rates, the shear stress makes the dispersion change from a layer-ordered structure to a disordered structure (of clusters) and the dispersion is shearthickening. The shear rate that makes the dispersion change from shear-thinning to shear-thickening is defined as the critical shear rate (CSR) (Sun et al, 2004).

When the swelling time was 1 day, the polymer microgel particles were rigid and could not deform easily. At this case, if shear rate was higher than the CSR, the clusters of the particles could not be formed easily, and the dispersion was just slight shear-thickening. With the increase of the swelling time (5-20 days), more water entered the polymer microgel particles, the hydration degree and apparent size of the particles increased. As a result, the volume fraction of the particles increased and the particles deformed more easily. In this case, if the shear rate was higher than the CSR, the polymer micro-gel dispersion changed from a layer-ordered structure to a disordered structure, and at the same time, the intermolecular forces or hydrogen bonds which exist between carbonamide groups of the polymer and water molecules made the particles form clusters. Therefore, the dispersions are shear-thickening. With the shear rate increasing $\left(>1,215 \mathrm{~s}^{-1}\right)$, the shear stress not only caused the micro-gels to form new clusters but also broke the formed clusters. At this time, the dispersions showed different shear-thinning properties at different swelling times.

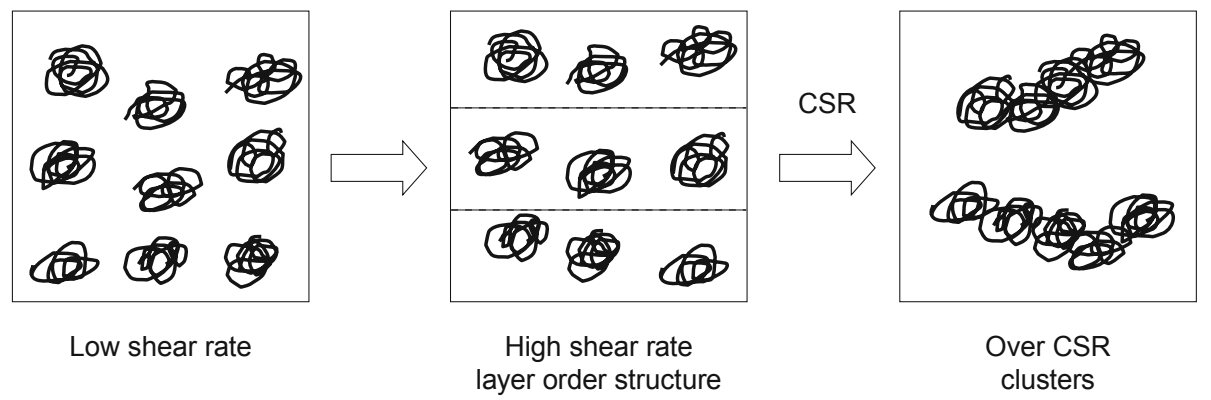

Fig. 2 Shear-thickening process of polymer micro-gel dispersion

The process of the polymer dissolving in water includes two stages. The first stage is that water molecules diffuse into the polymer particles and the particles swell. The second stage is that the swollen particles dissolve in water and become macromolecular coils. Like the polymer particles, when the time of the polymer micro-gel particles swelling in water is long enough, the particles can dissolve and form macromolecular coils in water. In this case, the volume fraction of the polymer coils is great and the polymer microgel particles or polymer coils can deform easily. On the other hand, part of the polymer segments of the polymer coils and the cross-linking points of the polymer micro-gel could be broken due to oxygen degradation of the polymer. Therefore, the dispersion that had swollen for 30 days is close to a Newtonian fluid, neither shear-thickening nor shear-thinning.

\section{2 $\mathrm{NaCl}$ concentration}

Fig. 3 shows the viscosity vs. the shear rate of the polymer micro-gel dispersion swollen 10 days at $40{ }^{\circ} \mathrm{C}$, with a polymer micro-gel concentration of $100 \mathrm{mg} \cdot \mathrm{kg}^{-1}$, at different $\mathrm{NaCl}$ concentrations.

The results showed that the rheological properties of the polymer micro-gel dispersion were significantly influenced by the salinity. In the shear rate range of $5 \mathrm{~s}^{-1}$ to $1,600 \mathrm{~s}^{-1}$, when the $\mathrm{NaCl}$ concentration was $0-5,000 \mathrm{mg} \cdot \mathrm{kg}^{-1}$, the apparent viscosity of the dispersions decreased with an increase of 


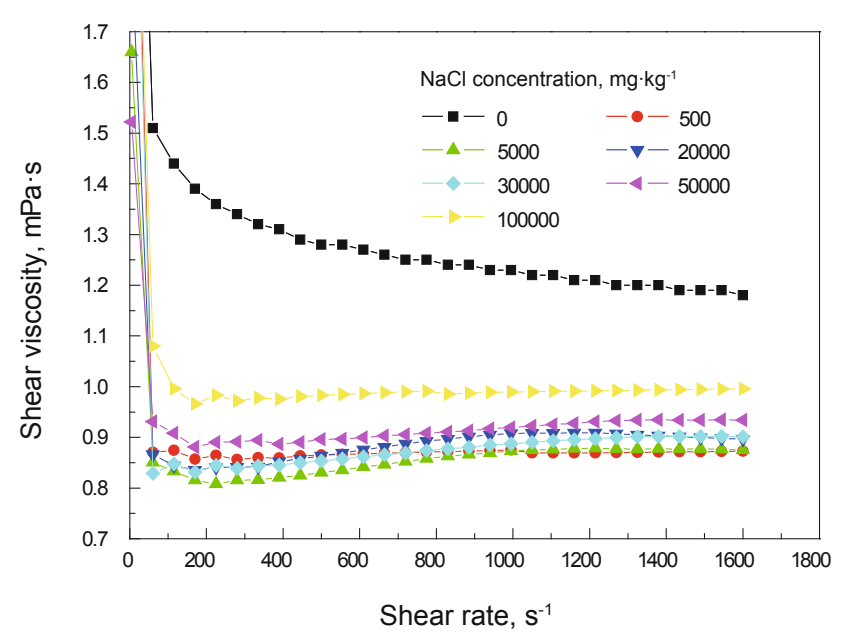

Fig. 3 Viscosity curves of polymer micro-gel dispersionat different $\mathrm{NaCl}$ concentrations

$\mathrm{NaCl}$ concentration. When the $\mathrm{NaCl}$ concentration was greater than $20,000 \mathrm{mg} \cdot \mathrm{kg}^{-1}$, the apparent viscosity of the dispersions increased with an increase of $\mathrm{NaCl}$ concentration.

The polymer micro-gel dispersion in non-saline water was shear-thinning and its apparent viscosity was the largest in comparison with the other dispersions with the same microgel concentration. In the shear rate range of $60 \mathrm{~s}^{-1}$ to $1,600 \mathrm{~s}^{-1}$, $n$ was 0.93 . In the same shear rate range, the dispersion with low $\mathrm{NaCl}$ concentration of $500 \mathrm{mg} \cdot \mathrm{kg}^{-1}$ was close to a Newtonian fluid, that is, its apparent viscosity almost remains constant with $n$ being 1.01. In the $\mathrm{NaCl}$ concentration range of 5,000 to $20,000 \mathrm{mg} \cdot \mathrm{kg}^{-1}$, the dispersion showed different rheological properties: In the low shear rate range (60-170 $\left.\mathrm{s}^{-1}\right)$, the dispersion was shear-thinning; In the high shear rate range $\left(390-1,215 \mathrm{~s}^{-1}\right)$, the dispersion was shear-thickening. For the dispersion with $5,000 \mathrm{mg} \cdot \mathrm{kg}^{-1} \mathrm{NaCl}, n$ was 1.07 ; for the dispersion with $20,000 \mathrm{mg} \cdot \mathrm{kg}^{-1} \mathrm{NaCl}, n$ was 1.06 ; and for the dispersion with $100,000 \mathrm{mg} \cdot \mathrm{kg}^{-1} \mathrm{NaCl}, n$ was 1.01 . These results showed that, in the $\mathrm{NaCl}$ concentration range of 5,000$100,000 \mathrm{mg} \cdot \mathrm{kg}^{-1}$, with the increase of $\mathrm{NaCl}$ concentration, the shear-thickening degree of the dispersion decreased.

In the low $\mathrm{NaCl}$ concentration range of $0-500 \mathrm{mg} \cdot \mathrm{kg}^{-1}$, the ionic strength was small, and the apparent size of the hydrated micro-gels was large, hence the hydrated microgels were stretched and oriented more easily by shear stress (Lei et al, 1994). Meanwhile, the thick electrical double layer and hydration layer of the micro-gels protected the microgels against aggregating under the shear stress. Therefore, the dispersion was shear-thinning.

In the $\mathrm{NaCl}$ concentration rang of $5,000 \mathrm{mg} \cdot \mathrm{kg}^{-1}$ to 20,000 $\mathrm{mg} \cdot \mathrm{kg}^{-1}$, the ionic strength became large in comparison with that in the $\mathrm{NaCl}$ concentration of $0-500 \mathrm{mg} \cdot \mathrm{kg}^{-1}$, and the electrical double layer and hydration layer of the micro-gels became thin. The apparent size of the hydrated micro-gel was small and the micro-gels were firm, hence it was more difficult for the micro-gels to deform. The volume fraction of the micro-gels in the dispersion decreased, as a result, the micro-gels aggregated to form temporary clusters under the action of shear stress, and the dispersions are shearthickening.
In $\mathrm{NaCl}$ concentrations above $20,000 \mathrm{mg} \cdot \mathrm{kg}^{-1}$ and up to $100,000 \mathrm{mg} \cdot \mathrm{kg}^{-1}$, the ionic strength was much larger, and the electrical double layer and hydration layer of the microgels became thinner. At this case, the micro-gels cannot be dispersed very well and were aggregated easily. The apparent size of the aggregated micro-gels (clusters), and the apparent viscosity of the dispersions, was greater.

\subsection{Swelling temperature}

Table 1 shows the non-Newtonian index $n$ of the polymer micro-gel dispersion, with a $\mathrm{NaCl}$ concentration of 2,000 $\mathrm{mg} \cdot \mathrm{kg}^{-1}$ and a polymer micro-gel concentration of 100 $\mathrm{mg} \cdot \mathrm{kg}^{-1}$, at different swelling times at $40{ }^{\circ} \mathrm{C}$ and $90{ }^{\circ} \mathrm{C}$. The shear rates in the experiments were measured in the range of $500 \mathrm{~s}^{-1}$ to $1,995 \mathrm{~s}^{-1}$.

The results showed that at the beginning of the swelling, the dispersion which was swelled at $40{ }^{\circ} \mathrm{C}$ is slightly shearthickening. The $n$ of the dispersion that had swollen 1 day was 1.02 . With increasing swelling time, the degree of the shear-thickening of the dispersion increased firstly and then decreased. The $n$ of the dispersion that had swelled 10 days was 1.06 , and then decreased to 1.02 after the dispersion had swollen 20 days.

Table 1 The $n$ of the polymer micro-gel dispersion at different swelling times

\begin{tabular}{cccccccc}
\hline \multirow{2}{*}{$\begin{array}{c}\text { Swelling temperature } \\
{ }^{\circ} \mathrm{C}\end{array}$} & \multicolumn{6}{c}{$n$ at different swelling times } \\
\cline { 2 - 7 } & $1 \mathrm{~d}$ & $5 \mathrm{~d}$ & $10 \mathrm{~d}$ & $15 \mathrm{~d}$ & $20 \mathrm{~d}$ & $30 \mathrm{~d}$ \\
\hline 40 & 1.02 & 1.04 & 1.06 & 1.05 & 1.02 & 1.02 \\
90 & 1.02 & 1.09 & 1.01 & 1.02 & 1.02 & 1.01 \\
\hline
\end{tabular}

At the beginning of the swelling, the $90{ }^{\circ} \mathrm{C}$ polymer micro-gel dispersion was slightly shear-thickening too. The $n$ of the dispersion that had swollen for 1 day was 1.02 . With increasing swelling time, the rapidity of the shear-thickening of the dispersion was much greater at $90{ }^{\circ} \mathrm{C}$ than at $40{ }^{\circ} \mathrm{C}$. The $n$ of the dispersion that had swollen 5 days increased up to the maximum 1.09 and then decreased rapidly. After the dispersion had swollen 10 days, the dispersion was close to a Newton fluid.

The experimental results showed that the rheological property of the dispersions that swelled at different temperatures was different. The rapidity of the shear-thickening of the dispersion swelled at $90^{\circ} \mathrm{C}$ was faster than that at $40{ }^{\circ} \mathrm{C}$, and the time achieving the equilibrium swelling is shorter at $90{ }^{\circ} \mathrm{C}$ than at $40{ }^{\circ} \mathrm{C}$. The time when the dispersion showed the highest shearthickening was 5 days at $90{ }^{\circ} \mathrm{C}$, and 10 days at $40{ }^{\circ} \mathrm{C}$.

\subsection{Micro-gel concentration}

Fig. 4 shows the viscosity vs. the shear rate of the polymer micro-gel dispersions swollen 10 days at $40{ }^{\circ} \mathrm{C}$, with 2,000 $\mathrm{mg} \cdot \mathrm{kg}^{-1} \mathrm{NaCl}$, at different micro-gel concentrations. The $n$ of the dispersions are shown in Table 2.

The results showed that with the increase of the polymer micro-gel concentration, the apparent viscosity of the 
Table 2 The $n$ of polymer micro-gel dispersions with different micro-gel concentration at different shear rate ranges

\begin{tabular}{|c|c|c|c|c|}
\hline \multirow{2}{*}{$\begin{array}{l}\text { Micro-gel concentration } \\
\mathrm{mg} \cdot \mathrm{kg}^{-1}\end{array}$} & \multicolumn{4}{|c|}{$n$ at different shear rate ranges } \\
\hline & $60-170 \mathrm{~s}^{-1}$ & $335-1160 \mathrm{~s}^{-1}$ & $1380-1600 \mathrm{~s}^{-1}$ & CSR, $\mathrm{s}^{-1}$ \\
\hline 50 & 0.86 & 1.01 & 1.01 & 170 \\
\hline 100 & 0.88 & 1.06 & 0.99 & 335 \\
\hline 600 & 0.97 & 1.08 & 0.93 & 170 \\
\hline 900 & 1.02 & 1.05 & 0.94 & 995 \\
\hline
\end{tabular}

dispersions increased.

In the low shear rate range $\left(60-170 \mathrm{~s}^{-1}\right)$, the polymer micro-gel dispersions with low micro-gel concentration were shear-thinning. With the increase of the polymer micro-gel concentration, the shear-thinning property of the dispersions was weakened. With the polymer micro-gel concentration of $900 \mathrm{mg} \cdot \mathrm{kg}^{-1}$, the dispersion was shear-thickening. With the polymer micro-gel concentration of $1,500 \mathrm{mg} \cdot \mathrm{kg}^{-1}$, the dispersion was shear-thinning again.

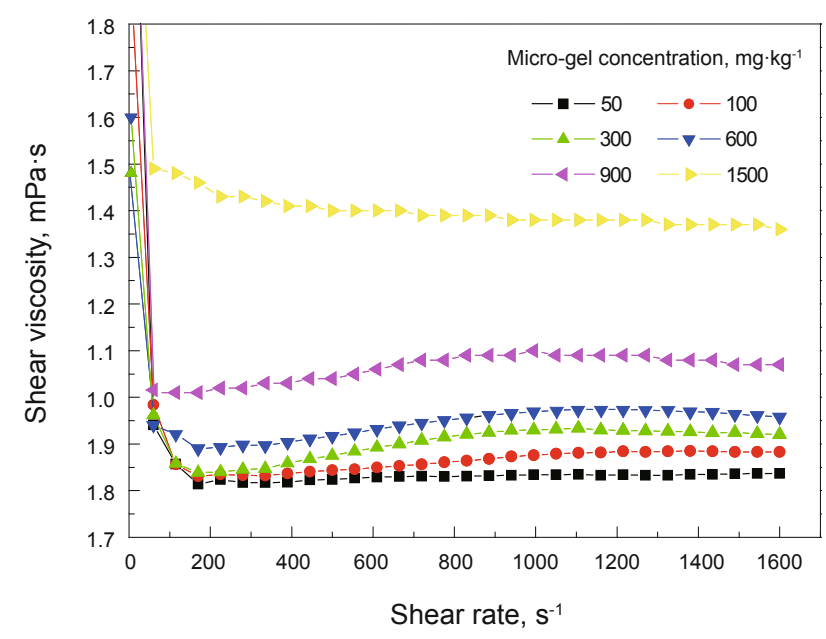

Fig. 4 Viscosity curves of polymer micro-gel dispersions with different micro-gel concentrations

In the high shear rate range $\left(335-1,600 \mathrm{~s}^{-1}\right)$, with the increase of the polymer micro-gel concentration the dispersions showed more evident shear-thickening. For the dispersion with $50 \mathrm{mg} \cdot \mathrm{kg}^{-1}$ micro-gel, the non-Newton index $n$ was 1.01 ; For the dispersions with $300 \mathrm{mg} \cdot \mathrm{kg}^{-1}$ and 600 $\mathrm{mg} \cdot \mathrm{kg}^{-1}$ micro-gel, the maximum value of the $n$ was 1.08 . With the polymer micro-gel concentration of $900 \mathrm{mg} \cdot \mathrm{kg}^{-1}$, the shear-thickening property of the dispersion was weakened, and the $n$ of the dispersion was 1.05 . When the polymer micro-gel concentration was increased further, the dispersions became shear-thinning. For example, the $n$ of the dispersion with $1,500 \mathrm{mg} \cdot \mathrm{kg}^{-1}$ micro-gel was 0.97 .

In the even higher shear rate range (1,380-1,600 $\left.\mathrm{s}^{-1}\right)$, the apparent viscosity of the polymer micro-gel dispersion with low micro-gel concentration $\left(50 \mathrm{mg} \cdot \mathrm{kg}^{-1}\right)$ did not vary with shear rate, and the dispersion was close to Newtonian fluid. The dispersions with higher micro-gel concentration (100-500 $\mathrm{mg} \cdot \mathrm{kg}^{-1}$ ) were shear-thinning.

The results showed that the rheological property of the dispersions with different micro-gel concentration was different. In the low shear-rate range (60-170 $\left.\mathrm{s}^{-1}\right)$, the low concentration micro-gels dispersed well in the dispersions, and the hydrated micro-gels were stretched and oriented easily by shear stress. In this case, the polymer micro-gel dispersion was shear-thinning. With the increase of the polymer microgel concentration, the micro-gels easily overlapped each other, and the shear-thinning property of the dispersion was weakened. With the polymer micro-gel concentration of $900 \mathrm{mg} \cdot \mathrm{kg}^{-1}$, the dispersion was shear-thickening. When the polymer micro-gel concentration was large enough $(1,500$ $\mathrm{mg} \cdot \mathrm{kg}^{-1}$ ), the micro-gels overlapped and aggregated to form network structures. The micro-gels with the network structure can entirely move easily, so the dispersion was shear-thinning again.

In the high shear-rate range (335-1,160 $\left.\mathrm{s}^{-1}\right)$, when shear rate increased above CSR, the micro-gels in the dispersion changed from a layer order structure to a disordered structure and can form clusters easily. With the increase of the polymer micro-gel concentration, the volume fraction of the microgels in the dispersion increased too. Therefore, the shearthickening property of the dispersions was enhanced. When the polymer micro-gel concentration increased up to 900 $\mathrm{mg} \cdot \mathrm{kg}^{-1}$, the micro-gels could overlap each other to form network structures easily and resulting in a flow as a body. So the shear-thickening property of the dispersion weakened. When the polymer micro-gel concentration was 1,500 $\mathrm{mg} \cdot \mathrm{kg}^{-1}$, the dispersion was shear-thinning.

In the even higher shear rate range $\left(1,380-1,600 \mathrm{~s}^{-1}\right)$, the shear stress not only caused the micro-gels to form new clusters but also broke the formed clusters. At the low microgel concentration $\left(50 \mathrm{mg} \cdot \mathrm{kg}^{-1}\right)$, the number of the polymer micro-gel particles was small, and the volume fraction of the micro-gels in the dispersion was not great. Therefore, the high shear rate could not affect the rheological property of the polymer micro-gel dispersion significantly. With the increase of the polymer micro-gel concentration, the volume fraction of the micro-gels in the dispersion increased too, 
and the formed network structure of the micro-gels could be broken easily by the high shear rate. So the polymer microgel dispersions showed different shear-thinning properties.

\section{Conclusions}

This research shows that the rheological properties of the polymer micro-gel dispersion is complicated. With the increase of swelling time and $\mathrm{NaCl}$ concentration, the polymer micro-gel dispersion changes from shear-thickening to a Newtonian liquid. At high swelling temperature, the time of the dispersion showing shear-thickening is shorter than that at low swelling temperature. With the increase of polymer micro-gel concentration, the polymer micro-gel dispersion changes from shear-thickening to shear-thinning.

\section{References}

Brady J F and Bossis G. The rheology of concentrated suspensions of spheres in simple shear flow by numerical simulation. J. Fluid Mechanics. 1985. 155: 105-129

Barnes H A, Hutton J F and Walters K. An Introduction to Rheology. New York: Elsevier Science Publishers B V. 1989. 15-119

Dong Z X, Wu Z L, Lin M Q, et al. Difference between linked polymer solution and polymer solution. Acta Petrolei Sinica (Petroleum Processing Section). 2004. 20(6): 8-13 (in Chinese)

Han X Z, Li M Y, Lin M Q, et al. Hydration properties analysis of a linked polymer micro-sphere system. Oilfield Chemistry. 2006. 23(2): 162-165 (in Chinese)

Han X Z, Li M Y, Guo J X, et al. Plugging property of linked polymer micro-spheres dispersed system. Journal of the University of Petroleum, China (Edition of Natural Science). 2008. 32(4): 127-131 (in Chinese)

Hoffman R L. Discontinuous and dilatant viscosity behavior in concentrated suspensions I. Observation of a flow instability. Transactions of the Society of Rheology. 1972. 16: 155-173

Hoffman R L. Discontinuous and dilatant viscosity behavior in concentrated suspensions III. Necessary conditions for their occurrence in viscometric flows. Advances in Colloid and Interface Science. 1982. 17(1): 161-184
Lei G L, Liu Y N and Xu C F. A new calculation method for relative permeability from polymer displacement experiment. Journal of the University of Petroleum, China (Edition of Natural Science).1994. 18: 100-103 (in Chinese)

Li M Y, Lin M Q, Zheng X Y, et al. Linked polymer solution as an indepth permeability control agent: laboratory study and field test. Oilfield Chemistry. 2000. 17(2): 144-147 (in Chinese)

Li M Y, Dong Z X, Lin M Q, et al. A study on the size and conformation of linked polymer coils. Journal of Petroleum Science and Engineering. 2004. 41: 213-219

Lin M Q, Sun A J, Dong Z X, et al. Study on properties of the linked polymer solution with low polymer concentration. Acta Phys. Chim. Sin. 2004. 20(3): 285-289 (in Chinese)

Lin M Q, Dong Z X, Li M Y, et al. Al NMR studies on HPAM/AlCit crosslinking system with low concentration polymer. Chemical Journal of Chinese Universities. 2007. (8): 1573-1576 (in Chinese)

Lin M Q, Wang Z J, Li M Y, et al. Thermal stability of linked polymer solution. Acta Petrolei Sinica (Petroleum Processing Section). 2008. 24(1): 112-116 (in Chinese)

Luo X H, Lin M Q, Dong Z X, et al. Study of factors influencing plugging performance of LPS. Membrane Science and Technology. 2006. 26(1): 88-91 (in Chinese)

Ma H X, Lin M Q, Li M Y, et al. Study of properties of linked polymer micro-spheres. Applied Chemical Industry. 2006. 35(76): 453-455 (in Chinese)

Sun A J, Wu Z L, Lin M Q, et al. Rheological properties of linked polymer solution made of low concentration partially hydrolyzed polyacrylamide and aluminum citrate. Journal of the University of Petroleum, China (Edition of Natural Science). 2004. 28(5): 65-69 (in Chinese)

Sun Z B, Li M Y, Guo J X, et al. Study of mechanism of plugging porous media of linked polymer solution. Polymeric Materials Science \& Engineering. 2005. 21(2): 225-228, 232 (in Chinese)

Wang D L and Xiao J H. Application of deep-profile control and displacement technology of a crosslinked polymer micro-sphere system. Petroleum Geology and Recovery Efficiency. 2008. 15(2): 82-86 (in Chinese)

Zong H, Lin M Q, Li N, et al. Study of influence factors on the plugging property of cross-linked polymer micro-ball. Applied Chemical Industry. 2007. 36(7): 693-695 (in Chinese)

(Edited by Zhu Xiuqin) 